\title{
Identitas Dakwah Perempuan dengan Techno-Religion
}

\author{
Ellys Lestari Pambayun \\ Fakultas Dakwah, Institut PTIQ Jakarta \\ (email: ellyslestari@ptiq.ac.id)
}

\begin{abstract}
The issue that is the focus of this paper is the phenomenon of identity formation that is built through da'wah conveyed by women on social media, such as the Gender Studies Community (Ustazah Nur Rodiah), the Niqab Squad (Indardari and Dina Nurlina), and Mumpuni Handayekti. The ustazahs who understand Islam seem to be a reference for the public because of their understanding and mastery of verses, hadiths, religious studies, and interpretations which are the content of their platforms at any time. On the one hand, the convenience of social media as a source of da'wah content has triggered the emergence of "millennial ustazah identity" as the spirit of women to ground the da'wah movement. On the other hand, being a "religious agent" that positions women as preachers still gets stereotypes from the dominant environment. These activities of KGI, Niqab Squad, and Mumpuni Handayekti attempt to be studied through the conceptual approaches of Technoreligion, Gender Communication Identity, and Helena Cixous Writing Feminist Criticism. This study uses the netnography method on three da'wah content on YouTube, Instagram, and Facebook. The results of the study provide findings that in the technology concept, social media has the potential to expand and structure the religious behavior of KGI, Niqab Squad and Mumpuni Handayekti preachers as part of millennial society. Especially in obtaining messages and religious identity of these preachers in the concept of Gender Communication Identity, explaining that the formation of their identity on social media: KGI (youtube and instagram), Niqab Squad (youtube, instagram, facebook), and Mumpuni Handayekti (youtube) can be traced through I and Me characters who are awakened through their behavior or symbolic activities with the mad'u (audience). And, in the perspective of Hélène Cixous explains that the formation of the identity of "millennial ustazah" indicates a sexist and ideological structure: KGI (identity: critical and scientific studies), Niqab Squad (identity: stylist and millennial), and Mumpuni Handayekti (identity: local feminine). assumed to have independence, authenticity, transformation, and strength of its own. Although they have their own uniqueness and strengths that masculine don't have: sharpness of taste and language that is different from men's (language that emerges from the media).
\end{abstract}

\section{Keywords:}

Ustazah, Copas WA Reality, Identity Perspective, Communication 


\begin{abstract}
Abstrak
Persoalan yang menjadi fokus dalam tulisan ini adalah, fenomena pembentukan identitas yang dibangun melalui dakwah yang disampaikan perempuan di media sosial, seperti Komunitas Ngaji Kajian Gender (Ustazah Nur Rodiah), Niqab Squad (Indardari dan Dina Nurlina), dan Mumpuni Handayekti. Para ustazah yang paham agama Islam seakan menjadi acuan masyarakat karena pemahamannya dan penguasaan mereka pada ayat-ayat, hadits-hadits, kajian agama, dan tafsir-tafsir yang setiap waktu menjadi konten platfom mereka. Di satu sisi, kemudahan media sosial sebagai salah satu sumber konten dakwah, memicu munculnya "identitas ustazah milenial" sebagai semangat kaum perempuan membumikan gerakan dakwah. Di sisi lain, menjadi "agen agama" yang memosisikan perempuan sebagai pendakwah masih mendapat stereotip dari lingkungan dominan. Aktivitas dakwah KGI, Niqab Squad, dan Mumpuni Handayekti ini berupaya untuk dikaji melalui pendekatan konsep Technoreligion, Identitas Komunikasi Gender, dan Kritik Feminis Writing Helena Cixous. Penelitian ini menggunakan metode netnografi pada tiga konten dakwah di youtube, instagram, an facebook. Hasil kajian memberikan temuan bahwa secara konsep teknoreligion, media sosial berpotensi memperluas dan menstrukturkan perilaku keagamaan para pendakwah KGI, Niqab Squad dan Mumpuni Handayekti sebagai bagian masyarakat milenial. Khususnya dalam memperoleh pesan dan identitas keagamaan para pendakwah ini secara konsep Identitas Komunikasi Gender, menjelaskan bahwa pembentukan identitas mereka di medsos: KGI (youtube dan instagram), Niqab Squad (youtube, instagram, facebook), dan Mumpuni Handayekti (youtube) dapat ditelusuri melalui karakter I dan Me yang terbangun melalui perilaku mereka atau aktivitas simbolik dengan dengan para mad'u (pemirsanya). Dan, dalam perspektif Hélène Cixous menjelaskan bahwa pembentukan identitas "ustazah milenial" mengindikasikan sebuah bangunan seksis dan ideologis: KGI (identitas: kajian kritis dan ilmiah), Niqab Squad (identitas: stylist dan milenial), dan Mumpuni Handayekti (identitas: feminin lokal) diasumsikan memiliki independensi, otentisitas, tranformitas, dan kekuatan sendiri. Meski mereka memiliki keunikan sendiri dan kekuatan yang tak dimiliki maskulin : ketajaman rasa dan bahasa yang berbeda dengan laki-laki (bahasa yang muncul dari media).
\end{abstract}

\title{
Kata Kunci:
}

Ustazah, Realitas Copas WA, Perspektif Identitas, Komunikasi

\section{Pendahuluan}

Perempuan dan dakwah di era milenial ini semakin memperlihatkan geliatnya di platfom media sosial. Baik pendakwah (daiah) yang sudah terkenal maupun yang masih sebatas lokal. Tema dan gaya komunikasinya beragam. Ada yang unik, nyentrik, kalem, berapi-api, tegas, dan penuh canda, bahkan kritis. Meski beragam, 
Identitas Dakwah Perempuan dengan Techno-Religion para pendakwah perempuan ini memiliki misi bersama 'amar ma'ruf nahi munkar tentunya. Dan yang lebih kental terlihat dari aneka gaya dan pola dakwah mereka sama-sama mengonstruksi identitas Islam.

Kehadiran gerakan dakwah online perempuan dapat dianggap sebagai reaksi terhadap tren konten yang mendominasi ruang maya: cybersex, propaganda teroris, termasuk agitasi kebencian. Gerakan dakwah perempuan ini tentunya lebih aktif memosisikan diri sebagai wali akhlak yang berjuang untuk memperkenalkan akhlak Islam dan memerangi kerusakan akhlak. ${ }^{1}$ Salah satunya penggunaan Instagram oleh anggota Komunitas Hijabers Indonesia yang memiliki misi agar hijabers menggunakan Instagram sebagai panggung untuk melakukan kelas menengah untuk berdakwah, yang mereka anggap sebagai salah satu tugas utama mereka sebagai Muslim. Instagram, bagi perempuan Muslim merupakan instrumen kendali atas tubuh mereka dalam penampilan pos-feminis mereka di media sosial. Identitas yang dikontruksi budaya digital global yang dinamis sebagai bidang komunikasi Islam yang berubah - dan meengindikasikan "integrasi habitus" yang diidentifikasi media sosial. $^{2}$

Para daiyah, terutama kaum mudanya, telah melakukan transisi dari media cetak ke pengguna media online. ${ }^{3}$ Realitas ini umumnya dimulai setelah diperkenalkannya ponsel pintar dan tablet, yang saat ini digunakan sebagai perangkat utama untuk aktivitas online. Kecanggihan teknologi media telah melahirkan aplikasi mobile olah pesan cepat, seperti WhatsApp, facebook, twiteer, blog, youtube, dan sebagainya. Barendregt mengatakan bahwa penggunaan media sosial, khususnya WhatsApp untuk dakwah adalah contoh bagaimana praktik telepon seluler global menjadi 'didomestikasi, diindonesia, dan diislamkan'.4

\footnotetext{
${ }^{1}$ Eva F. Nisa, Social Media and the Birth of an Islamic Social Movement, PMCID, (2018), Vol. 46 (134), $24-43$.

${ }^{2}$ Alila Pramiyanti \& Emma Baulch, Hijabers on Instagram: Using Visual Social Media to Construct the Ideal Muslim Woman, MPRA Paper, (Germany: University Library of Munich, 2018).

${ }^{3}$ Nurkinan, Dampak Media Online Terhadap Perkembangan Media Konvensional, Jurnal Politikom Indonesiana, (November 2017), Vol. 2 No. 2

${ }^{4}$ Bart Barendregt, "Sex, Cannibals, and the Language of Cool: Indonesian Tales of the Phone and Modernity”, The Information Society, (2008), Vol. 24(3), 160-170.
} 
Masyarakat Indonesia, khusus Muslim telah mengislamkan media seluler, terbukti dari produk-produk yang ditawarkan melalui teknologi seluler yang berkaitan dengan Islam, seperti Al-Qur'an Seluler, Mobile Syariah Banking, kuliner, dan marketplace yang menawarkan produk Islami. ${ }^{5}$

Identitas dakwah perempuan semakin tampak menguat sejak jatuhnya rezim Suharto pada tahun 1998, lanskap media Indonesia telah berubah secara radikal. Negara ini sekarang menjadi lebih untuk menyuarakan rasa kesalehan mereka. ${ }^{6}$ Pada tahun 2017, Kepala Badan Nasional Penanggulangan Terorisme ( BNPT) Komisaris Jenderal Suhardi Alius dan Ketua Umum Fatayat NU Anggia Ermarini bahkan telah berhasil melantik 500 daiyah atau juru dakwah perempuan anti-radikalisme Fatayat NU di Bandung. ${ }^{7}$ Selain itu, terdapat pula kegiatan Pra Halaqah Perempuan Ulama 2020 yang diinisiasi Pusat Studi Pesantren (PSP) yang berhasil mengumpulkan 20 perempuan ulama yang mewakili 20 pesantren dari berbagai daerah melalui aplikasi Zoom dengan tema 'Jalan Dakwah di Media Sosial dan Penguatan Literasi Pesantren' ${ }^{8}$

Berbagai ruang diskusi, konsultasi, advokasi, dan penyebaran pesan-pesan dakwah tak terbendung bermunculan memenuhi laman daring dan darling para asatizah Indonesia. Di antara kelompok dakwah perempuan adalah Komunitas Ngaji Kajian Gender Islam (KGI) yang didirikan Nur Rofi'ah telah memiliki gerakan dakwah kritis dan analitis di berbagai platform media, seperti Zoom, Skype, Google Meet, Instagram, dan Youtube. Selain itu, magdalene.co. yang dikenal publik karena dakwahnya memiliki keberpihakan pada perempuan dan minoritas lain seperti LQBT, dan komunitas lainnya. Sedangkan, gerakan dakwah perorangan di media sosial, bisa dijumpai dari sekian muslimah muda yang pandangan atau komentarnya terhadap fenomena keagamaan di era modern nyaring di media sosial, Durrotun

\footnotetext{
${ }^{5}$ Eva F. Nisa, Social Media and the Birth of an Islamic Social Movement, 43..

${ }^{6}$ Hanny Savitri Hartono, Virtually (Im)moral: Pious Indonesian Muslim Women's Use of Facebook, Asian Studies Review, (2018), Vol.42, Issu 1, 39-52.

${ }^{7}$ https://www.nu.or.id/post/read/120380/sejumlah-ibu-nyai-muda-siap-ramaikan-dakwah-di-medsos

${ }^{8} \mathrm{https}: / /$ nasional.kompas.com/read/2017/04/21/21590011/bnpt.dan.fatayat.lantik.500.juru.dakwah.pere mpuan.anti-radikalisme
} 
Identitas Dakwah Perempuan dengan Techno-Religion Nafisah Zaim (Pesantren Kauman Lasem), Ienas Tsuroiya (Pesantren Raudlatut Thalibin Leteh Rembang) pada Channel YouTube Pondok Kauman Lasem yang mengangkat tema pengajian kitab Tafsir Al Ibriz yang dipadukan Tafsir Iklil dan Tafsir Ibnu Katsir. ${ }^{9}$ Selain itu, Kalis Mardiasih dan Esty Diah Imaniar dari Univesitas Sebelas Maret (UNS) Solo, Youtube Ukhti Mega Official,10 juga dari para selebriti tanah air seperti Mamah Dedeh, Ustazah Lulu, Peggy Melati Sukma, Umi Pipik, Oky Setiana Dewi, dan lainnya.

Misi dakwah dengan keragamannya menempatkan para daiah pada identitas tertentu: satu sisi ada yang menantang batas-batas identitas yang "berbeda" (keberpihakannya) dan lainnya fokus pada agama secara kritis atau dogmatis/normaif, bahkan ada yang cenderung fundamental dan politis. Kajian ini mencoba mengeksplorasi identitas utama yang menghubungkan gerakan pendakwah perempuan dengan keterlibatan mereka pada media sosial. Pertama, menjadi pendakwah dan aktif berpartisipasi dalam media sosial sebagai tantangan terhadap batas-batas identitas feminin mereka. Oleh karena itu, para daiah utri yang memposisikan diri secara jelas dalam kerangka identitas Islam terlihat jarang tertarik pada politik dan dakwah yang “keras” yang dapat mereduksi identitas feminitas yang terhormat. Karena, meski masih dalam ruang "nyaman" pun para daiah ini tetap kerap dan masih mengalami diskriminasi dan pelecehan karena konten dakwah dan penampilan mereka. ${ }^{11}$

Realitas "pembedaan", stereotip dan prasangka sosial yang direpresentasikan publik maya (netizen) terhadap perempuan yang berdakwah (asatizah) , 12 menjadi pertanyaan penting dalam kajian ini. Karena itu, kajian ini berfokus pada relitas pembentukan identitas pendakwah perempuan dan keterlibatan mereka dalam

\footnotetext{
https://www.NU.Or.Id/Post/Read/120380/Sejumlah-Ibu-Nyai-Muda-Siap-Ramaikan-Dakwah-diMedsos

${ }^{10}$ Lihat sumber: Https://Www.Nu.Or.Id/Post/Read/120380/Sejumlah-Ibu-Nyai-Muda-SiapRamaikan-Dakwah-Di-Medsos, 29 Mei 2020:

${ }^{11}$ Wawancara Pra Observasi Dengan Lina Marlina, seorng ustazah dari Tangerang Selatan.

12 Yvonne Haddad, Jane Smith, And Kathleen Moore, Muslim Women In America: The Challenge Of Islamic Identity Today, (Oxford: Oxford University Press, 2006), 190.
} 
dunia media sosial. Konsep 'kerja identitas' digunakan untuk menggarisbawahi aspek dinamis dari konstruksi identitas. Studi ini didasarkan pada penelusuran secara netnografi, pendekatan dakwah bil technoreligion, dan teori identitas komunikasi gender, pada gerakan dakwah perempuan di media sosial, baik komunitas maupun perorangan. Tujuan kajian adalah menganalisis konstruksi identitas dakwah perempuan dalam menyikapi realitas masyarakat yang semakin terbelah dan kompleks dalam keberagamaannya.

\section{Tinjauan Pustaka}

Kajian dari Prima Ayu Mahanani yang melaporkan bahwa teknologi berdampak besar bagi interaksi para pendakwah perempuan Salafi, khususnya melalui aplikasi WhatsApp. Kajian ini bertujuan melakukan mediatisasi perempuan Salafi dalam dakwahnya untuk mematahkan semakin kuatnya dominasi logika media dalam agama. Konsep yang digunakan dari Stighjarvard pada tahapan institusi. Metode pnelitian dengan pendekatan etnografi melalui wawancara. Hasil penelitian menunjukkan terdapat perubahan budaya dalam aktivitas dakwah oleh perempuan Salafi. Media telah menjadi bagian tak terpisahkan dari Perempuan Salafi dan juga sebagai struktur besar dalam ManhajSalafi. ${ }^{13}$ Kajian selanjutnya dari A'isyah dan Rezki Putri Nur Aini dari UIN Sunan Kalijaga yang mengangkat masalah sejauh mana peran influencer Muslimah dalam menggunakan media baru, untuk meningkatkan ideologi dan pemikiran Islam antara sekularisme dan fundamentalisme masyarakat perkotaan dan generasi milenial kelas menengah. Peneliti menggunakan pendekatan netnografik pada akun Ria Ricis (@ riaricis1795) dengan representasi perempuan yang sekuler dan akun Anisa Rahma (@ anisarahma_12) dengan representasi motivator migran perempuan, Wafiq Malik (@wafiqmalik) dengan representasi dominasi eksistensi perempuan bercadar dan Gita Savitri Devi (@gitasav) dengan representasi perempuan berintelektual tinggi. Hasil

\footnotetext{
${ }^{13}$ Prima Ayu Mahanani, Mediatisasi Pada Aktivitas Dakwah Perempuan Salafi, Jurnal Pendidikan Islam dan Dakwah, (2016), Vol.1, No.02.
} 
Identitas Dakwah Perempuan dengan Techno-Religion

penelitian memperlihatkan bahwa selalu muncul bentuk-bentuk perlawanan terhadap klaim Islam tentang penertiban perempuan dengan mengambil simpati publik terkait dakwah budaya gerakan Tarbiyah tetapi juga berdampak pada manfaat sosial ekonomi. ${ }^{14}$

\section{Kerangka Teoretis}

Pendekatan Dakwah bil Teknoreligion, secara ontologis diasumsikan bahwa saat dakwah bersinggungan dengan teknologi maka keberadaanya berada dalam wilayah objek material dakwah. Dakwah sebagai eksistensi yang memiliki makna, dan teknologi sebagai materi suatu realitas. Realitas yang paling jelas pada saat melihat agama bersahabat akrab dengan teknologi, di mana semua persoalan agama mengendarai teknologi untuk mentransformasikan identitas, ide-ide dan maknamakna yang disodorkan agama. Para ustazah kondang, pemula, selebritias, aktivis ormas, tradisional, kalangan radikal, bahkan dari kaum awam seperti emak-emak berlomba memasang identitas di akun-akun, bermukin di situs-situs free dan berbayar, asik membangun identitas dan citra diri melaui diskusi hangat dan terbuka bahkan panas di kanal-kanal medsos, kebanyakan melalui ponsel. Doktrin missionary religion, adalah prinsip Islam yang kini semakin memperlihatkan identitasnya dalam wujud yang luar biasa canggih yang disebut dengan tech-religion. ${ }^{15}$ Seperti yang dilaporkan dari hasil penelitian Muchammad Fachrurozi (2015) bahwa fenomena teknoreligion paling tidak dalam dua hal, yaitu berpotensi memperluas peran teknologi media dalam menstrukturkan perilaku agama masyarakat modern, khususnya dalam memperoleh pesan dan identitas agama. Kedua, menggambarkan fenomena "pendelegasian" wewenang pihak otoritas agama atas teknologi sehingga

${ }^{14}$ A'isyah \& Rezki Putri Nur Aini, Media Representation Of Muslimah Influencer In Frame Of Dakwah Journal Of Research On Religious Education And Culture, Jurnal Penelitian Pendidikan, Agama, dan Kebudayaan, (2020), Vol.6. No.2.

${ }^{15} \mathrm{SE}$. George. Religion and Technology in the $21^{\text {st }}$ Century: Faith in the E-World. (Australia: University of South Australia, 2006). 
menggambarkan relasi yang bersifat negosiatif antara agen manusia dan agen teknologi. ${ }^{16}$

Hoover (2006) mengungkapkan bahwa perkembangan mutakhir memperlihatkan fakta bahwa perbincangan hari ini mengenai agama tidak lagi dipisahkan dengan media dan teknologi. Secara bersamaan, agama dan media telah saling berkelindan dalam pengalaman identitas kultural khalayak media. ${ }^{17}$ Hal ini dikonfirmasi pula oleh Morgan (2008) yang mencatat perkembangan kajian tentang hubungan antara agama dan media yang demikian pesat. Menurutnya, sebelum tahun 1980- an bidang kajian agama lebih banyak ditemukan pada identitas agamawan, para penyeru, dan pendidik agama. Namun, identitas ini kemudian mengalami perubahan signifikan. Antropologi, cultural studies, media studies, visual and material culture, film studies, dan religious studies merupakan beberapa disiplin yang kelak mengkaji tentang identitas agama dan teknologi media secara serius. ${ }^{18}$

Sebelum di media sosial, pembentukan identitas keagamaan sosial ini biasa ditransmisikan melalaui khutbah, kitabah, radio, televisi, dan film, bahkan di kampus-kampus, lapangan, majelis besar,dan sebagainya. Aktivitas dakwah ini bisa disebut paradigma Tabligh, yaitu pesan-pesan dakwah ditransmisikan secara luas dan massif, pada identitas yang bersifat anomin, tak terbatas, dan heterogen. ${ }^{19}$ Atau, bisa dikatakan bentuk praktiknya sendiri bersifat dakwah ummah yaitu proses penyampaian pesan-pesan dakwah kepada pada mad'u yang beridentitas massa (masyarakat umum) dengan berbagai media personal dan massa. ${ }^{20}$

Teori Identitas Komunikasi Gender sebagai landasan konseptual, menyatakan bahwa pembentukan identitas perempuan dapat ditelusuri melalui pemikiran Margareth Mead $^{21}$ tentang I dan Me. Pembentukan identitas ini dibangun melalui

\footnotetext{
${ }^{16}$ Muchammad Fachrurozi. "SMS Tauhid sebagai Teknoreligion Perspektif Teknokultur atas Penyebaran tausyiah Agama Melalui SMS”, Jurnal Sosioteknologi, (Desember 2015), Vol. 14, No 3.

${ }_{17}$ S.M., Hoover, Religion and the Media in the 21st Century. Trípodos , (2012), Vol.29, 27-35.

${ }^{18}$ David Morgan,.(ed.). Keywords in Religion, Media and Culture (London: Routledge, 2008).

${ }^{19}$ Ali Aziz, 2016. Ilmu Dakwah, Edisi Revisi. Jakarta: Penerbit Kencana

${ }^{20}$ Wahidin Saputra. 2011. Pengantar Ilmu Dakwah. Jakarata:PT Rajagrafindo Persada

${ }^{21}$ Margareth Mead dalam Julia T. Wood, 2000. Communication Theories in Action 2nd Edition. USA: Wadsworth Thomson Learning.
} 
Identitas Dakwah Perempuan dengan Techno-Religion dakwah media sosial, yang dpat menjadi pembeda dari dakwah secara konvensional atau tatap muka langsung. Di Barat tahun 2009, membidani misi agama di media sosial telah dilegitimasi negara ${ }^{22}$. Apalagi kuatnya keamanan layanan obrolan di ponsel seperti whatsapp membuat penggunanya mudah dipercaya meski sulit dipantau, dibandingkan facebook dan twitter. Tapi yang pasti, plaform ini bisa digunakan untuk menyebarkan berbagai pesan agama, ideologi, dan berita, tanpa bisa dipantau oleh pemerintah atau bahkan perusahaan itu sendiri. ${ }^{23}$

Helena Cioux, seorang feminis posmodern melalui konsep feminine writing pada fenomena "konstruksi identitas ustazah" melaui medsos membuka penjelasan bahwa "dakwah bil medsos" memuat jangan sampai pesan-pesan yang hampa, tanpa jiwa karena ketidakjelasan sumber otoritatif, indenpendensi, otentisitas, melanggar kaidah moderasi juga memperkuat rasa ketidakadilan dan dominasi kelompok. Feminin writing, memang konsep yang menghendaki perempuan menjadi pembicara atau penulis aktif bukan penulis pasif sehingga transformasi pengetahuan dan emansipatois bisa terus berjalan di muka bumi. ${ }^{24}$

\section{Metode Penelitian}

Kajian ini menggunakan pendakatan metode peneletian kualitatif netnografi pada tiga akun (platform) yang berbeda gaya komunikasi yaitu: Komunitas Ngaji Kajian Gender (KGI) yang dipimpin Ustazah Nur Rofiah, Ustazah Mumpuni Hadayekti, dan Niqab Squad pimpinan Ustazah Indadari.

\section{Implikasi dan Pembahasan}

Dalam teori identitas komunikasi gender, perempuan adalah bagian yang sangat signifikan keberadaanya di dunia maya. Pada kajian ini narasumber

\footnotetext{
22 Wawancara online Juli-Agustus 2019 dengan Muhammad Fathoni, pegiat dakwah di media sosial

${ }^{23}$ Yudianto, 2017. Penggunaan Whatsapp Kian Mencengangkan. DetikInet, hlm.1. Diambil tanggal 31 agustus 2017. http://inet.detik.com/cyberlife/

${ }^{24}$ Helena Cixous dalam Ellys Lestari Pambayun, Komunikasi Feminis Mencari Tuhan, (ed) Abdul Muid Nawawi, Melangitkan Manusisa: Apresiasi Pemikiran Prof.Dr. Nasaruddin Umar, MA, (Jakarta: PTIQ Press, 2019).
} 
pendakwah perempuan yang mengisi ruang maya di antaranya Komunitas Ngaji Kajian Gender Islam (KGI) pimpinan Ustazah Nurofiah, Niqab Squad pimpinan Ustazah Indadari, dan Ustazah Mumpuni Handayekti (youtuber), yang hadir sesuai kapasitas, kebutuhan, dan kepentingan mereka di tengah umatnya. Ungkapan pemikiran dan perasaan para pendakwah perempuan (daiyah) di ruang maya (facebook, youtube, WA, dan lainnya) ini tidak hanya sebatas deskripsi ilmiah dengan mengeksplorasi berbagai teori dan perspektif yang mereka kuasai, namun melalui ruang medsos mereka berbagi ilmu, tausyiah, inspirasi, uneg - uneg, semangat bahkan kesempatan. Namun, terlepas dari sejumlah perkembangan globalisasi yang menjadikan KGI, Niqab Squad, dan Mumpuni Handayekti, sebagai pendakwah perempuan bisa lebih bebas dalam berekspresi, pada kenyataannya pemahaman mereka ini masih terbatas dengan nilai-nilai sosial tertentu yang secara tidak langsung membentengi pemikiran masyarakat dalam mengkonstruksikan seorang perempuan menjadi pendakwah. Berangkat dari pemikiran di atas, KGI, Niqab Squad dan Mumpuni Handayekti muncul adanya semangat untuk membebaskan diri atas perlakuan dan stereotip yang diterimanya, salah satunya adalah mewujudkan kesetaraan bagi perempuan melalui sharing tausiyah dan konten-konten agama di medsos.

Elisabeth K. Kelan memberikan argumennya bahwa pandangan diskursif tentang gender sekarang ini lebih mengarah pada upaya memunculkan diri sebagai identitas subjek melalui sosialisasi nilai-nilai gender yang disebarkannya, sering disebut konsep gender socialization. Konsep ini menjelaskan bagaimana perempuan begitu terikat dengan nilai dan norma yang dikonstruksi secara sosial, dan melalui interaksi atau sosialisiasi, eksistensinya menyeruak dalam gerakan yang melahirkan wacana gender dan mengkonstruksi posisi perempuan untuk menjadi sosok ideal sesuai perspektif masyarakat. ${ }^{25}$ Pembentukan identitas "agamis" atau mengidentifikasi para daiyah (KGI, Niqab Squad, dan Mumpuni Handatyekti) pada

\footnotetext{
${ }^{25}$ Elisabeth K. Kelan, "Discursive Theories of Gender." Encyclopedia of Gender and Society. (USA:SAGE Publications, 2008).
} 
dasarnya tidak terlepas dari proses sosialisasi dan komunikasi yang dibangun secara sosial, seperti di ruang medsos.

Secara konseptual, pembentukan identitas di ruang medsos melalui penyebaran konten agama, dapat ditelusuri melalui pemikiran Margareth Mead tentang $I$ dan $M e .{ }^{26}$ KGI dalam kegiatannya menjelaskan adanya pembentukan identitas I dan Me yang terbangun dalam lingkungan komunitas sosial melalui kajian yang bertema "Gender dan Jenis Kelamin”, "Keadilan Hakiki Perempuan”, “Level Kesadaran dan Kemanusiaan Perempuan", dan "Revolusi Islam atas Kemanusiaan Perempuan", dan lainnya. Untuk publik yang lebih umum, Ngaji KGI sempat menggelar diskusi yang disiarkan langsung melalui akun Instagram @ngaji_kgi. Diskusi bertajuk Ngabuburit KGI itu mengambil dua bahasan yang sedang tren saat ini, "Bidadari Surga" dan "Kritis Beragama seperti Aisyah RA". Kajian KGI memiliki katakter dalam membentuk perilaku individu atau aktivitas simbolik yang muncul dari peleburan antara karakter dakwah yang ilmiah dan kritis yang sesuai dengan pemikiran komunikan (mad'unya) berdasarkan pengalaman pada lingkungan sosial mereka yang diasumsikan masih kental ideologi patriarkis, yang disebut interaksionisme simbolik. Pada, Karakter I (Aku), yang ditampilkan para pendakwah Niqab Squad (Indadari dan Diana Nualina) merupakan sosok yang memosisikan dirinya sebagai subjek atau komunikator melalui identitas "bercadar yang kreatif" yang dibentuknya. Konsep I ini dikarakterisasikan cenderung kondusif: kelompok Niqab Squad dan para anggota berperilaku secara terorganisasi, terarah, dan tidak spontan dalam mensoialisasikan para perempuan untuk bercadar ke seluruh Indoneia bahkan ke mancanegara (Taiwan, Malaysia, New York, Australia, dan lainnya). Sedangkan, karakter Me secara message production, disampaikan KGI baru sebatas di ruang kuliah, seminar, workshop, dan masjid karena itu youtube, instagram dan podcas adalah media KGI yang sangat efektif untuk mediseminasi konten kajian KGI;

\footnotetext{
${ }^{26}$ Margareth Mead dalam Ellys Lestari Pambayun, One Stop Qualitative Research Methodology in Communication, (Jakarta: Lentera Cendekia, 2013).
} 
Niqab Squad dan Mumpuni Handayekti dalam rangka memahami (fi anfusihim) diri pribadi komunikan (mad'u) mereka dalam interaksi langsung (sebelum pandemi Covid-19) di masjid dan ruang-ruang majelis, gedung pertemuan secara gathering; dan Mumpuni Handayekti melalui aksi panggung lokal, di mana semua kegiatannya ini divideokan dan diunggah ke youtube dan instagram para penontonnya sehingga komunikasi semakin terjalin di antara mereka. Karakter para ustazah dari KGI, Niqab Squad dan Mumpuni Handayekti ini menjelaskan kecenderungan mereka untuk berperilaku atau berkomunikasi sesuai dengan sikap mad'unya. Jelasnya, Me (para daiyah) KGI, Niqab, dan Mumpuni Handayekti adalah individu yang terikat secara sosial: selalu dikontrol dan diperhatikan lingkungan sosialnya.

Prinsip I yang diposisikan Mumpuni Handayekti di youtube dan instagram yang kebanyakan diunggah para penontonnya ini telah menjelama menjadi subjek yang mempu berinteraksi atau berproses dalam ruang publik dengan karakternya yang lucu dan ceplas-ceplos serta banyak gimik yang mengundang tawa mad'unya. Keberadaan Mumpuni secara individual atau sebagai I dalam dakwahnya di medsos mengarahkan dirinya secara dominan (superior) untuk membentuk identitas dengan menyebar konten agama yang ngapak sesuai bahasa daerah yag ia kuasai dan mad'u pahami (daeah eks Karisidenan Banyumas Jawa Tengah). Saat Mumpuni sebagai Me, ia memahami cara bagaimana mad'u melihat dirinya sebagai pendakwah lokal. Dari pengamatan penulis, ustazah Nur Rofiah (KGI), Indardari (Niqab Squad, dan Mumpuni (ustazah bentukan Aksi Indosiar 2017) menurut analisis I and Me ini bisa bergantian, saling melengkapi, dan saling menggantikan sesuai persepsi terhadap identitas yang dibangunnya selama memberikan tausiyah kepada mad'u mereka.

Melaui message production posisi daiah KGI, Niqab Squad, dan Mumpuni di medsos menjelaskan sebagai komunikator yang bertugas untuk memproduksi pesan Islami di ruang publik luas secara masif secara lokal; kajian kritis dan tafsir klasik dan kontemporer (KGI) dengan menyertakan kutipan atau potongan dalil dan ayat dari Al-Qur'an dan hadis; Niqab Squad dengan aktif menggelar program keagamaan, nasehat, maupun muatan ajakan masuk pada kelompok atau menggunakan cadar di 134 | El Madani: Jurnal Dakwah dan Komunikasi Islam, Volume 1 No. 02 (2020) 
Identitas Dakwah Perempuan dengan Techno-Religion dalam medsos. Produksi pesan ini dijelaskan oleh Carla L. Fisher at.al sebagai cara menyusun dan menyandikan sebuah "konsensus" atas pesan informasi yang dihasilkan pada si penerima pesan, sekaligus menjawab seluruh pertanyaan yang berkaitan dengan pesan-pesan yang dihasilkan. ${ }^{27}$

Namun, para daiyah KGI, Niqab, dan Mumpuni dalam beberapa konten dan pernyataan di medsos mereka sebagai agen sebar (message producer) Islam bisa juga bersikap "bukan keranjang segala tahu". KGI (kesetaraan gender dalam tafsir AlQur'an yang kritis dan ilmiah), Niqab Squad (sosialisasi cadar yang seremonial dan milenial), dan Mumpuni Handayekti (akhlak masyarakat di wilayah domestik yang lucu dan atraktif) dengan mad'unya (message receiver) bisa memutus konten dan menolak dakwah yang tidak relevan dengan bidang mereka. Setidaknya menghentikan arus sebar (message flow) pemberitaan dan konten yang tidak sejalan dengan pemikiran mereka sehingga tidak terus bergulir dipublik. Khususnya, konten-konten agama yang tidak dipahami dan tak diketahui kebenarannya karena awam atau unskill (bukan bidangnya). Karena, perempuan yang beridentitas dan cerdas (un-false women) menurut Helena Cixous adalah yang mampu memberikan ucapan dan tulisan otentiknya, setidaknya melakukan self editor atau self selection pada pesan-pesan (dakwah) yang membanjirinya. ${ }^{28}$ Jika perempuan bisa saling mengingatkan dan memberi anjuran self edit atau seleksi pada konten dakwah berarti memberi jalan laju peredaran konten dakwah untuk lebih bermakna dan maslahat, selain itu seruang-seruan Islam di medsos bisa terus ditunggu dan diminati pemirsanya. Para daiyah sangat memahami sabda Nabi Muhammad saw: "Sampaikanlah (apa) yang berasal dariku walaupun satu ayat." (HR. Al-Bukhari, Ahmad, dan At-Tirmidzi). Selain, itu para daiyah KGI, Niqab Squad, dan Mumpuni Handayekti di media sosial adalah bentuk wujud persuasif dan impelementatif melalui firman Allah Swt, sebagai berikut:

\footnotetext{
${ }^{27}$ Carla L. Fisher, at.al., Communication and Mental Health: A Conversation from the CM Café, Journal Communication Monographs, (December, 2012), Vol. 79, Issue 4, 539-550.

${ }^{28}$ Helena Cixous dalam Ellys Lestari Pambayun, Komunikasi Feminis Mencari Tuhan, (ed) Abdul Muid Nawawi, Melangitkan Manusisa: Apresiasi Pemikiran Prof.Dr. Nasaruddin Umar, MA, 140.
} 


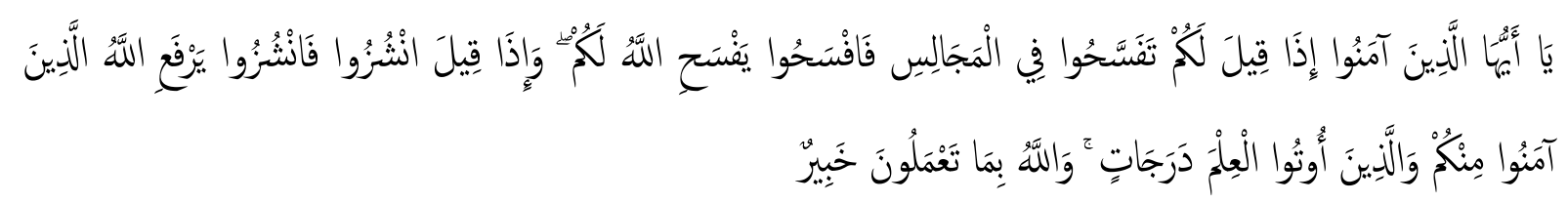

Artinya: "Wahai orang-orang yang beriman! Apabila dikatakan kepadamu, "Berilah kelapangan di dalam majelis-majelis," maka lapangkanlah, niscaya Allah akan memberi kelapangan untukmu. Dan apabila dikatakan, "Berdirilah kamu," maka berdirilah, niscaya Allah akan mengangkat (derajat) orang-orang yang beriman di antaramu dan orang-orang yang diberi ilmu beberapa derajat. Dan Allah Mahateliti apa yang kamu kerjakan." (QS. Al-Mujadilah: 11)

\section{Kesimpulan}

Teknologi, secara nyata dapat menjadi kendaraan membangun identitas Islam para pendakwah perempuan dari Komunitas Ngaji Kajian Gender Islam (Ustazah Nur Rofiah), Niqab Squad (Indardi dan Nina Nurlina), dan Mumpuni Handayekti secara revolusioner, bahkan global. Proses identitas yang bisa dijelmakan oleh platfom youtube, instagram, WA, dan lainnya dengan ratusan bahkan ribuan konten mereka yang bisa dihadirkannya kepada para publiknya tanpa sensor dan kontrol ketat dari pihak mana pun.. Konten dakwah KGI, Niqab Squad dan Mumpuni ini merepresentasikan dinamika keagamaan di era milenial yang ternyata menjadi "acuan" masyarakat Indonesia. Para daiyah KGI yang beridentitas kritis dan ilmiah, Niqab Squad yang stylist dan milenial, dan Mumpuni Handayekti yang beridentitas feminin dan lokal menjelma menjadi para posfeminis karena mampu menjadi agen sebar (message producer) Islam tanpa meninggalkan feminitas mereka. Bahkan, mereka mampu mendekonstruksi bahwa perempuan Islam bukanlah liyan yang pasif tapi progresif tanpa ambisius dalam naungan hakikat Al-Qur'an dan hadis. Secara perspektif $I$ and Me, para daiyah dari KGI, Niqab Squad, dan Mumpuni Handayekti adalah pelaku aktif dalam mentranmisikan Islam pada masyarakat melalui identitas yang mereka kibarkan di media sosial, baik yang sesungguhnya diinginkan maupun tidak diinginkan umatnya. 
Identitas Dakwah Perempuan dengan Techno-Religion

Secara posfeminis para daiyah dari KGI, Niqab Squad, dan Mumpuni Handayekti pembentukan identitas melalui dakwah mereka di medsos, mengindikasikan sebuah bangunan seksis dan ideologis: perempuan yang mampu menggunakan bahasanya sendiri (true women) karena tidak mengingkari independensi, otentisitas, tranformitas, dan kekuatannya sendiri.

\section{Daftar Pustaka}

A'isyah \& Aini, Rezki Putri Nur, Media Representation Of Muslimah Influencer In Frame Of Dakwah Journal Of Research On Religious Education And Culture, Jurnal Penelitian Pendidikan, Agama, dan Kebudayaan, (2020), Vol.6. No.2.

Aziz, Ali, Ilmu Dakwah, Edisi Revisi. (Jakarta: Penerbit Kencana, 2016).

Barendregt, Bart, "Sex, Cannibals, and the Language of Cool: Indonesian Tales of the Phone and Modernity", The Information Society, (2008), Vol. 24(3), 160-170.

Cixous, Helena dalam Pambayun, Ellys Lestari, “Komunikasi Feminis Mencari

Tuhan", (ed) Abdul Muid Nawawi, Melangitkan Manusisa: Apresiasi Pemikiran Prof.Dr. Nasaruddin Umar, MA, (Jakarta: PTIQ Press, 2019)

Fachrurozi, Muchammad, "SMS Tauhid sebagai Teknoreligion Perspektif

Teknokultur atas Penyebaran tausyiah Agama Melalui SMS". Jurnal Sosioteknologi, (Desember 2015), Vol. 14, No 3.

Fisher, Carla L., at.al., Communication and Mental Health: A Conversation from the CM Café, Journal Communication Monographs, (December, 2012), Vol. 79, Issue $4,539-550$.

George, SE., Religion and Technology in the $21^{\text {st }}$ Century: Faith in the E-World.

(Australia: University of South Australia, 2006).

Haddad, Yvonne, J. Smith, And K. Moore, Muslim Women In America: The Challenge Of Islamic Identity Today, (Oxford: Oxford University Press, 2006). Hartono, Hanny Savitri, Virtually (Im)moral: Pious Indonesian Muslim Women's Use of Facebook, Asian Studies Review, (2018), Vol.42, Issu 1, 39-52. 
Ellys Lestari Pambayun

https://www.nu.or.id/post/read/120380/sejumlah-ibu-nyai-muda-siap-ramaikandakwah-di-medsos

https://nasional.kompas.com/read/2017/04/21/21590011/bnpt.dan.fatayat.lantik.500.ju ru.dakwah.perempuan.anti-radikalisme

https://www.NU.Or.Id/Post/Read/120380/Sejumlah-Ibu-Nyai-Muda-Siap-Ramaikan-

Dakwah-di-Medsos

Https://Www.Nu.Or.Id/Post/Read/120380/Sejumlah-Ibu-Nyai-Muda-Siap-

Ramaikan-Dakwah-Di-Medsos, 29 Mei 2020.

http/: penggunaan Whatsapp Kian Mencengangkan. Diambil http://inet.detik.com/cyberlife/ Yudianto, 31 agustus 2017.

Kelan, Elisabeth K.. “Discursive Theories of Gender.” Encyclopedia of Gender and Society. (USA: SAGE Publications, 2008).

Mahanani, Prima Ayu, Mediatisasi Pada Aktivitas Dakwah Perempuan Salafi, Jurnal Pendidikan Islam dan Dakwah, (2016), Vol.1, No.02.

Mead, Margareth dalam Pambayun, Ellys Lestari, One Stop Qualitative Research Methodology in Communication, (Jakarta: Lentera Cendekia, 2013).

Nurkinan, Dampak Media Online Terhadap Perkembangan Media Konvensional, Jurnal Politikom Indonesiana, (November 2017), Vol. 2 No. 2.

Nisa, Eva F., Social Media and the Birth of an Islamic Social Movement, PMCID, (2018), Vol. 46 (134), 24-43.

Pramiyanti, Alila \& Baulch, Emma, Hijabers on Instagram: Using Visual Social Media to Construct the Ideal Muslim Woman, MPRA Paper, (Germany: University Library of Munich, 2018).

S.M., Hoover, Religion and the Media in the 21st Century. Trípodos , (2012), Vol.29, 2735.

Morgan, David.(ed.). Keywords in Religion, Media and Culture (London: Routledge, 2008).

Saputra, Wahidin, Pengantar Ilmu Dakwah. (Jakarata:PT Rajagrafindo Persada, 2011). 
Identitas Dakwah Perempuan dengan Techno-Religion

Wawancara Pra Observasi Dengan Lina Marlina, seorng ustazah dari Tangerang Selatan.

Wawancara online Juli-Agustus 2019 dengan Muhammad Fathoni, Pegiat Dakwah di Media Sosial 
Ellys Lestari Pambayun

140 | El Madani: Jurnal Dakwah dan Komunikasi Islam, Volume 1 No. 02 (2020) 